\title{
Arachnoid Cysts - Common and Uncommon Clinical Presentations and Radiological Features
}

\author{
Logan $\mathrm{C}^{1^{*}}$, Asadi $\mathrm{H}^{1,2}$, Kok HK ${ }^{1}$, Looby $\mathrm{S}^{1}, \mathrm{O}^{\prime} H a r e \mathrm{~A}^{1}$, Thornton $\mathrm{J}^{1}$ and Brennan $\mathrm{P}^{1}$ \\ ${ }^{1}$ Interventional Neuroradiology Service, Department of Radiology, Beaumont Hospital, Dublin 9, Ireland \\ ${ }^{2}$ School of Medicine, Faculty of Health, Deakin University, Pigdons Road, Waurn Ponds, VIC 3216, Australia
}

\author{
Correspondence to: \\ Caitriona Logan \\ Department of Radiology, Beaumont Hospital \\ Dublin 9, Ireland \\ Tel: +35318093000 \\ Fax: +35318098376982 \\ E-mail: caitrionalogan@gmail.com
}

Received: October 17, 2016

Accepted: December 12, 2016

Published: December 13, 2016

Citation: Logan C, Asadi H, Kok HK, Looby S, O'Hare A, et al. 2016. Arachnoid Cysts - Common and Uncommon Clinical Presentations and Radiological Features. J Neuroimaging Psychiatry Neurol 1(2): 79-84.

Copyright: ( 2016 Logan et al. This is an Open Access article distributed under the terms of the Creative Commons Attribution 4.0 International License (CC-BY) (http://creativecommons. org/licenses/by/4.0/) which permits commercial use, including reproduction, adaptation, and distribution of the article provided the original author and source are credited.

Published by United Scientific Group

\begin{abstract}
Arachnoid cysts are benign, extra axial, cystic lesions, formed due to congenital splitting of the arachnoid layer. They are often discovered incidentally, either by fetal cranial ultrasound or as an asymptomatic finding on subsequent neuroimaging studies in adulthood. In this article, we present a pictorial review demonstrating the typical imaging features for arachnoid cysts and also include imaging appearances of more atypical arachnoid cysts and their potential complications. We also discuss the epidemiology, pathogenesis, imaging features, differential diagnosis and clinical presentation of arachnoid cysts according to their location and present a brief outline of treatment options.
\end{abstract}

\section{Keywords}

Arachnoid layer, Mesoectodermal tissue, CSF

\section{Introduction}

Arachnoid cysts are the commonest cystic congenital abnormality of the brain [1]. They comprise $1 \%$ of intracranial masses [1]. Nowadays more arachnoid cysts are being discovered incidentally in the first few decades of life due to more widespread use of antenatal ultrasound and cross-sectional imaging modalities including CT and MRI [1-3]. Indeed the wide availability and improved quality of fetal and antenatal ultrasound means many arachnoid cysts are being discovered in utero $[4,5]$, even as early as the first trimester [6] and are accurately characterized in the neonate.

Al-Holou and colleagues reviewed almost 12,000 patients undergoing MR brain for all indications and arachnoid cysts were found in 309 patients (2.6\%) [7]. Another study of MR brains in 1000 healthy volunteers by Katzman et al. discovered arachnoid cysts in $0.3 \%$ [3]; however, multiple arachnoid cysts were found in very few (30) of the patients [7]. Overall, the literature generally quotes a prevalence of approximately $1-1.5 \%$ per patient in adults $[2,8,9]$ and a similar prevalence in children [7].

Arachnoid cysts are more common in males with a ratio of 2:1 [1,7] and are more frequently seen within the left hemisphere than the right [7]; however, there is no definite known cause for the left sided predominance nor their tendency to occur more frequently in the male population. Interestingly, studies of arachnoid cysts discovered antenatally and followed in the neonate, have often found them to undergo spontaneous regression and only progress in rare instances [4].

The commonest location of arachnoid cysts in the adult population (50$60 \%)$ is the middle cranial fossa or Sylvain fissure. Infratentorial arachnoid 
cysts are usually found within the cerebellopontine angle or retrocerebellar area and comprise $10 \%$ of arachnoid cysts, though some centers class cerebellopontine angle as a rare location. This location can be seen in the pediatric population $[1,4,8]$. They may be found in the suprasellar region in children in under $10 \%$ and even less commonly within the spine $[1,10,11]$.

In the relatively uncommon event of these cysts becoming symptomatic clinical manifestations are usually related to mass effect on adjacent structures including ventricular obstruction and subsequent hydrocephalus [7].

\section{Pathogenesis}

True congenital or primary arachnoid cysts develop due to splitting of the arachnoid at the cyst margin [12]. Embryologically, the meninges are derived from the mesoderm, and it is thought that the embryological process leading to the development of arachnoid cysts is the result of mesoectodermal tissue becoming detached during the folding of the neural tube which occurs around day 20 [8]. The lining of arachnoid cysts shares some morphological similarities to arachnoid granulations [12]. However, the inner membrane of arachnoid cysts have been found to have subtle ultrastructural differences to normal arachnoid membrane where the walls are found to be split at the cyst margins. There are also variant cell types within the cyst walls when compared to normal arachnoid, for example a thicker collagen layer and hyperplastic cells $[1,12]$.

Occasionally, arachnoid cysts occur in conjunction with other congenital anomalies, in particular involving the corpus callosum and there are possible associations between arachnoid cysts, callosal agenesis and Chiari malformations or with genetic disorders such as neurofibromatosis type 1 [8, 10]. The association with other congenital anomalies supports the theory that arachnoid cysts are indeed a congenital phenomenon. Secondary arachnoid cysts are thought to develop following head injury, meningitis or intracranial hemorrhage [8].

Arachnoid cysts most commonly remain stable in size and asymptomatic or occasionally regress and disappear entirely [4, 10]. They can, however expand causing mass effect on adjacent structures and remodeling of the calvarium [10]. Several theories exist as to why they sometimes expand, some studies hypothesizing that a one-way valve mechanism from the sub arachnoid cerebrospinal fluid (CSF) space to the cyst causes gradual enlargement $[1,8,13]$. MRI with cine loop recordings of CSF flow have been compared to intraoperative findings by Santamarta et al. to lend some weight to this theory [13].

Another theory proposes the presence of an osmotic gradient between the cyst and CSF which draws CSF in overtime causing it to expand. This theory lacks concrete evidence, however, as the osmotic properties of arachnoid cysts fluid seem for the most part to be similar to CSF, especially in primary congenital cysts. This theory may hold more weight in secondary cysts, where blood or inflammatory products increase the osmotic properties of the fluid $[8,14]$.
A third theory to explain the occasional expansion of arachnoid cysts is one that postulates a secretory mechanism of the cyst lining. The ultra-structural similarities to secretory arachnoid tissue makes this a possibility [15]. However, continuous expansion of arachnoid cysts is the exception, not the rule, making continuous secretion of cyst fluid unlikely to be the case for the majority of arachnoid cysts $[12,16]$.

\section{Diagnosis of Arachnoid Cysts}

From the diagnostic point of view, arachnoid cysts are typically a serendipitous discovery on imaging studies. On CT, they typically appear as extra-axial CSF density lesions causing local space occupying effect and occasionally calvarial remodeling $[1,10]$. They generally don't enhance following iodinated contrast administration, but may do so on delayed imaging [10]. Hounsfield attenuation values are generally between $10-20[1,8,10]$.

CT can be helpful to identify a cyst complicated by internal haemorrhage as the quickest and most readily available neuroimaging test. However, MRI is the definitive diagnostic tool for evaluation of arachnoid cysts as it confirms the extra-axial location and shows homogenous T2-weighted signal hyper intensity within the cyst similar to that of CSF. Fluid attenuated inversion recovery sequences (FLAIR) sequences are also useful to confirm the similarity of the cyst fluid to CSF $[10,17]$. Some centers report using Fiesta or other T2 thin modality of MRI help to see the arachnoid membranes better and their relation to other CSF spaces and their arachnoid membranes which can be helpful in planning fenestration surgeries. Diffusion weighted imaging is essential to differentiate arachnoid cysts, in particular from epidermoid cysts which can sometimes have a similar appearances $[17,18]$. Epidermoid cysts which display diffusion restriction and are less benign in their natural history, more frequently causing headaches, cranial nerve palsies or hemorrhage [10, 19].

Other differential diagnoses of arachnoid cysts include a subdural hygroma which is thought to relate to a chronic leak of CSF through damage to the meninges. These cysts will usually contain blood products, creating a difference in signal characteristics when compared to arachnoid cysts on T1-weighted and FLAIR sequences [10]. In addition, chronic subdural haematomas, as well as other non-neoplastic cysts such as neurenteric, neuroglial and porencephalic cysts $[1,8$, 10] can have a similar appearance. In a patient with a history of prior neurosurgical intervention, encephalomalacia in a resection cavity can have a similar appearance when expansion of the normal subarachnoid space occurs to fill the cavity [10].

Antenatal ultrasound can identify arachnoid cysts as early as 20 weeks using a trans-abdominal probe and as early as 13 weeks from a trans-vaginal approach [4,20]. Ultrasonographic appearances are that of a homogenous and hypoechoic cystic structure with no internal flow on Doppler imaging [20]. The majority discovered in utero tend to be inter-hemispheric and supra-tentorial [4]. When identified in utero, it is important to search for other structural anomalies that can mimic or co-exist with an arachnoid cyst, especially midline lesions 
such as corpus callosal agenesis, colloid cysts, Rathke's cleft cysts, glioependymal cysts and craniopharyngiomas [20]. Karyotyping and MRI can be then considered to out-rule such associated anomalies. It is important to make the distinction between arachnoid cysts and other less benign pathologies for parental counseling. Agenesis of the corpus callosum, for example may result in a clinical syndrome of seizures and developmental delay, whereas arachnoid cysts in isolation are far more likely to have a benign clinical course. Pierre Kahn et al. followed arachnoid cysts discovered in utero in 54 fetuses for four years. The cysts were found rarely to progress, sometimes to disappear completely and rarely to have any impact on the neurological status or development of the child [4].

\section{Typical Locations of Arachnoid Cysts and their Presenting Features}

\section{Middle cranial fossa and Sylvian fissure}

The commonest location of arachnoid cysts in the adult population $(50-60 \%)$ is the middle cranial fossa (usually temporal lobe) or Sylvian fissure [1, 4, 8]. See Figure 1.

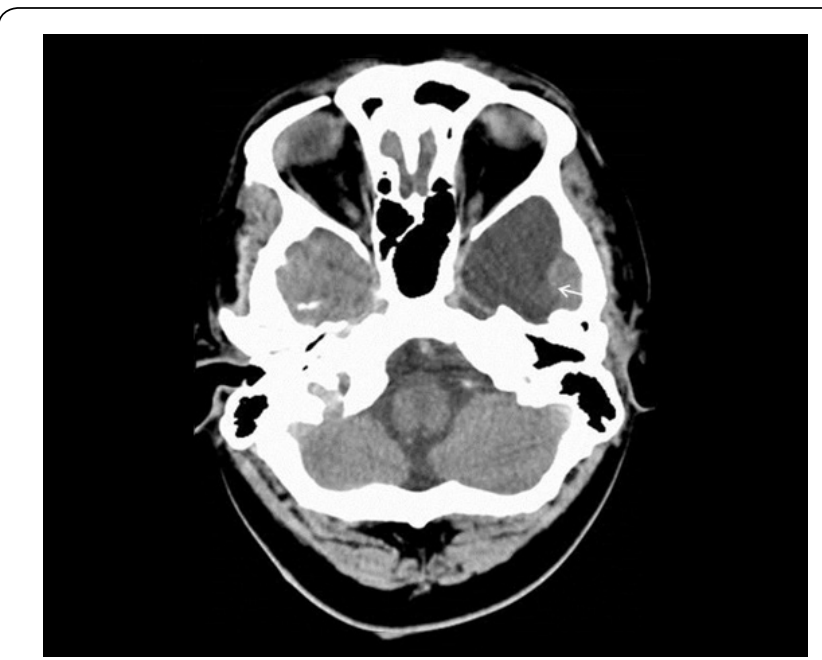

Figure 1: 22 year old male with head injury. Query intracranial haemorrhage.

Axial Non-contrast CT brain showing an extra-axial cyst within the left temporal lobe with mild mass effect (arrows). This way asymptomatic left temporal arachnoid cyst and no further imaging was required.

Middle cranial fossa arachnoid cysts were classified in 1989 by Gallassi based on 30 patients by CT into Types 1-3, small middle and large, with larger cysts occupying much of the middle cranial fossa [21]. In the relatively unusual cases where middle cranial fossa arachnoid cysts become symptomatic, they most commonly present with headache, seizures and motor deficits $[1,8,22]$. Symptom development is usually related to cyst enlargement and mass effect on adjacent structures. However, there is a less well proven link to epilepsy, nausea, dizziness and impaired cognition [23].

It is also postulated that juvenile middle cranial fossa arachnoid cysts may increase in size over time and expose the middle cerebral artery within the Sylvain fissure causing compression of it and resulting in underdevelopment of the temporal lobe [1]. Bitemporal arachnoid cysts are very rare and may occur in isolation or in association with glutaric aciduria; therefore, patients with bitemporal arachnoid cysts should be screened for GAT1 before any definitive surgical treatment is decided upon [24].

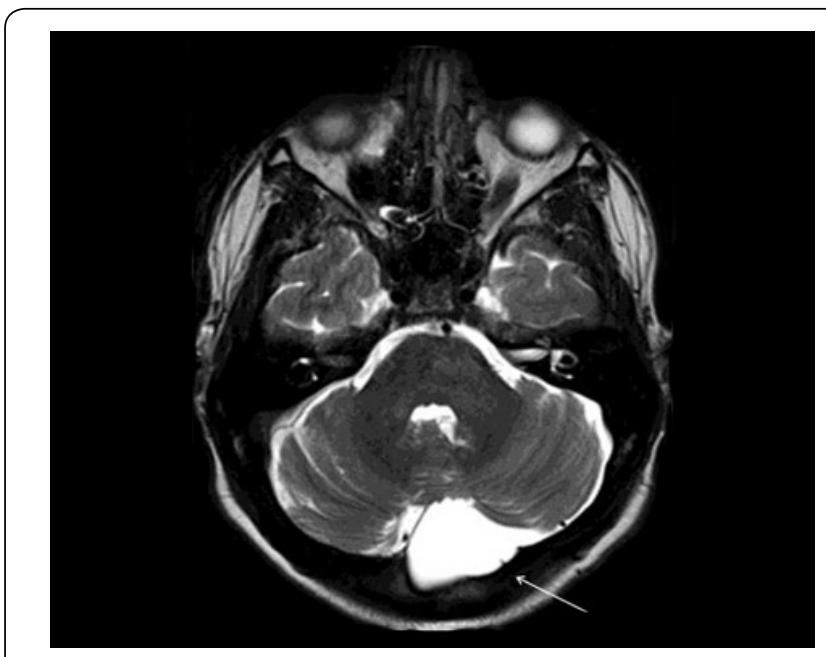

Figure 2: 30 year old male with relapsing, remitting multiple sclerosis. Incidental finding of posterior fossa T2 bright extra axial cyst (arrow).

\section{Infratentorial - cerebellopontine angle or retrocerebellar}

Infratentorial arachnoid cysts are occasionally seen in the pediatric population, and usually occur in a retrocerebellar region (Figure 2) or the cerebellopontine angle (Figure 3) comprising $10 \%$ of arachnoid cysts $[1,4,8]$. Symptoms will depend on location of the cyst and whether there is resultant mass effect. If obstruction to the normal flow of CSF occurs, an obstructive hydrocephalus will result which may cause macrocephaly and raised intracranial pressure $[1,8]$. Pressure on the cerebellum may cause nystagmus, gait disturbance, ataxia, incoordination or headache [1]. The cranial nerves that course through the cerebellopontine angle may also become compressed causing focal neurological deficits such as facial

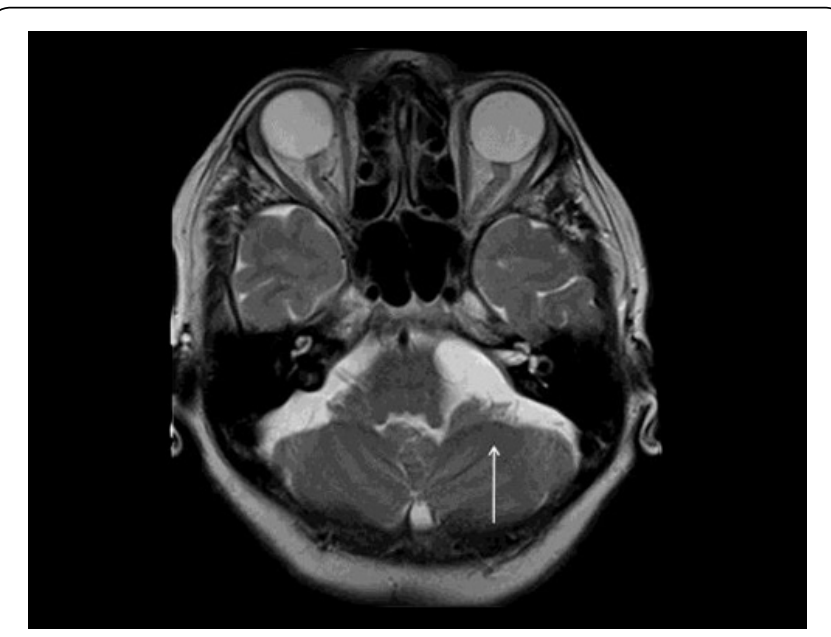

Figure 3: $77 \mathrm{y} / \mathrm{o}$ female presenting with tinnitus.

Axial T2 weighted MR (A) showing left cerebello-pontine angle arachnoid cyst. 
palsies or hearing loss [8]. These neurological deficits and symptoms will generally resolve with treatment of the cyst [25].

\section{Suprasellar}

Suprasellar or intrasellar arachnoid cysts (Figure 4) account for $10 \%$ of arachnoid cysts and are reported more frequently in the pediatric population [1]. Suprasellar arachnoid cysts may cause obstruction of the third ventricle at the level of the foramen of Monroe leading to hydrocephalus. Endocrine dysfunction with deficiencies in growth hormone and thyrotropin or disturbance to the hypothalamic-pituitarygonadal axis may occur in the case of suprasellar arachnoid cyst [26]. A rare "bobble-head-doll" syndrome has been described due to a suprasellar arachnoid cyst causing compression on the third ventricle and dorsal thalamic nuclei [27].

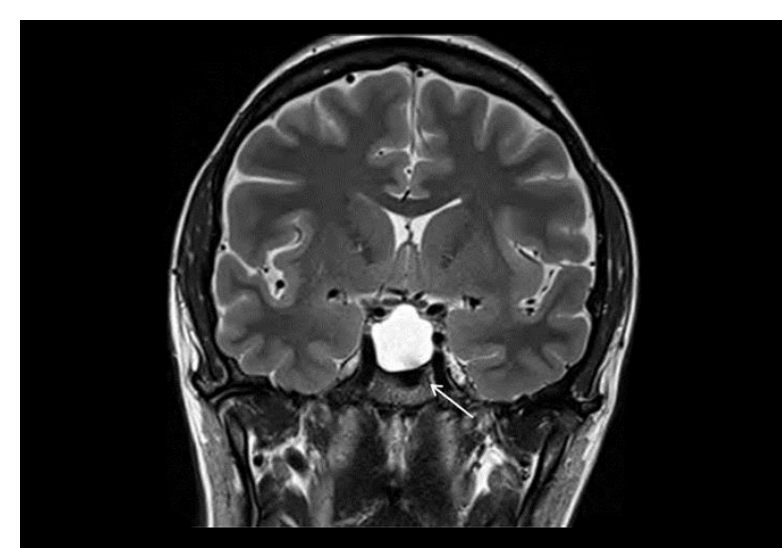

Figure 4: Incidental discovery on MRI brain in a 35 year old female presenting with dizzy spells.

Coronal T2 weighted MR showing a supra-cellar, homogeneously T2 bright arachnoid cyst.

\section{Spinal}

Spinal arachnoid cysts (Figure 5) are most common in the thoracic followed by the lumbar spine [28]. Spinal arachnoid cysts, like their intracranial counterparts may exhibit mass effect on adjacent structures resulting in symptoms and neurological signs. Slowly progressive myelopathy has been observed [29] manifesting with signs of ataxia, loss of power and spasticity. If the cyst continues to expand or is complicated by haemorrhage, cord compression can result [8].

\section{Management of arachnoid cysts}

The need for treatment of arachnoid cysts is controversial and is generally reserved for cysts proven to be causing focal neurologic symptoms or signs not attributable to other causes [8]. For this reason, a detailed history and examination along with appropriate imaging is essential in determining if the described symptoms are attributable to the cyst. It is worth mentioning that an unwanted effect of discovery of true "incidentalomas" is the causation of unnecessary concern to a patient that would otherwise likely never have been affected by the presence of an arachnoid cyst.

Arachnoid cysts may require emergency treatment in a number of scenarios. Acute obstructive hydrocephalus (Figure 6) may develop requiring emergency intervention, usually

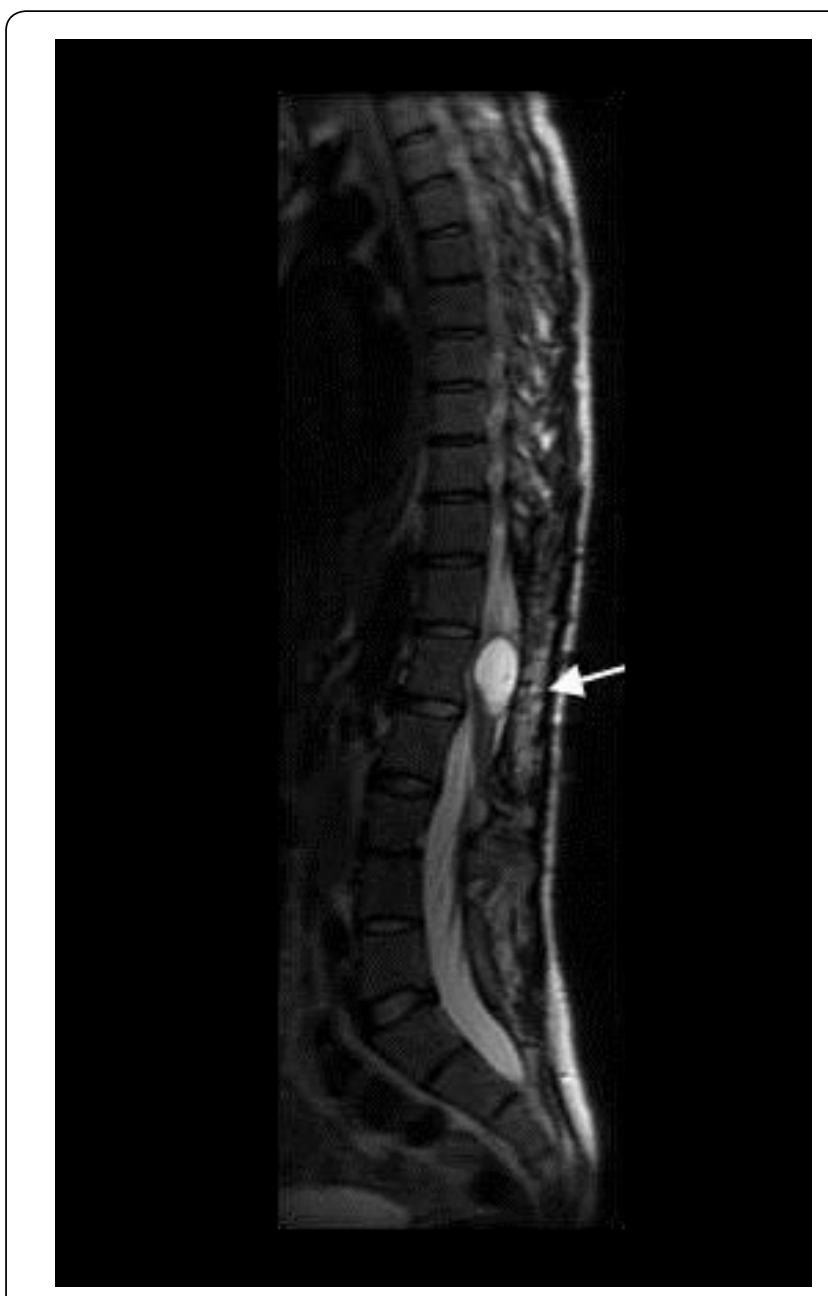

Figure 5: Sagittal T2 weighted MR lumbar spine showing a posterior extramedullary cyst at T12-L2 with mild mass effect. Findings consistent with a spinal arachnoid cyst.

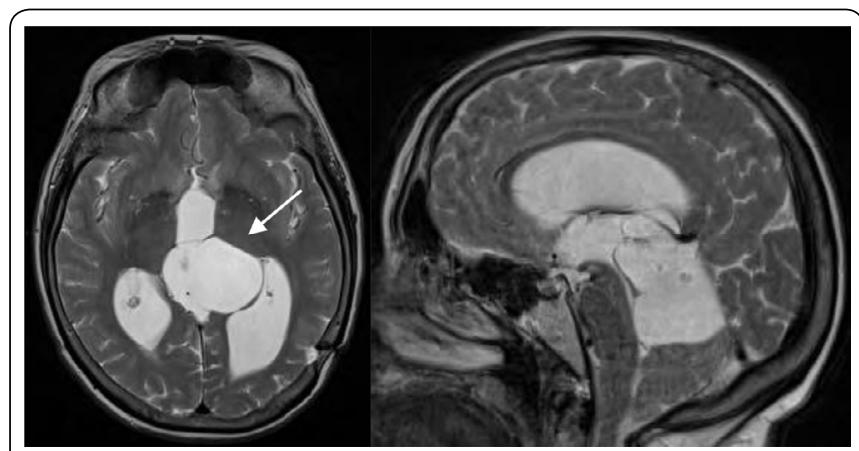

Figure 6: Axial T2 weighted MR images of an arachnoid cyst located at the quadrigeminal plate of the posterior midbrain (arrow) causing obstructive hydrocephalus. There is dilation of the third ventricle and of the lateral ventricles.

with shunting of CSF to relieve intracranial pressure. If acute myelopathy develops due to expansion or hemorrhage of a spinal arachnoid cyst (Figure 5), emergent intervention may avoid loss of neurological function [29]. Hemorrhage into a cyst, (Figure 7) for example, in the setting of a ruptured aneurysm may cause sudden onset headache and neurological deficit; hence, emergency treatment of the aneurysm, and not necessarily the cyst may then be required [22].

There is also a link speculated between arachnoid cysts 


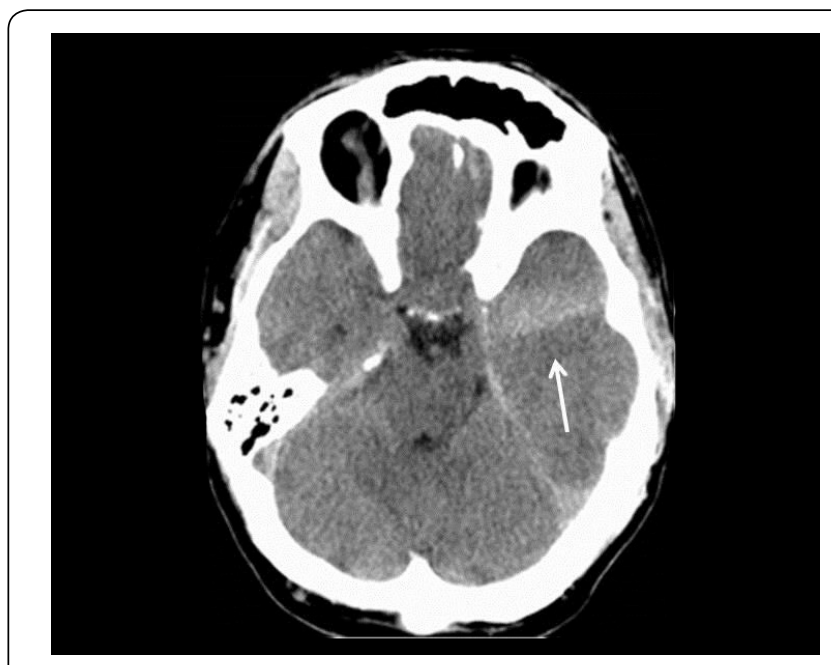

Figure 7: Axial non-contrast CT brain images showing acute haemorrhage into the left temporal arachnoid cyst.

and chronic subdural hematoma (Figure 9), particularly within the middle cranial fossa. This is thought to be related to small bridging vessels in the outer membrane of the cyst, which may give it a propensity to bleed [30]. In the setting of chronic symptoms and signs such as slowly progressive headache, motor deficit and ataxia, if they can be attributed to mass effect of the cyst without diagnostic uncertainty then treatment is indicated [8].

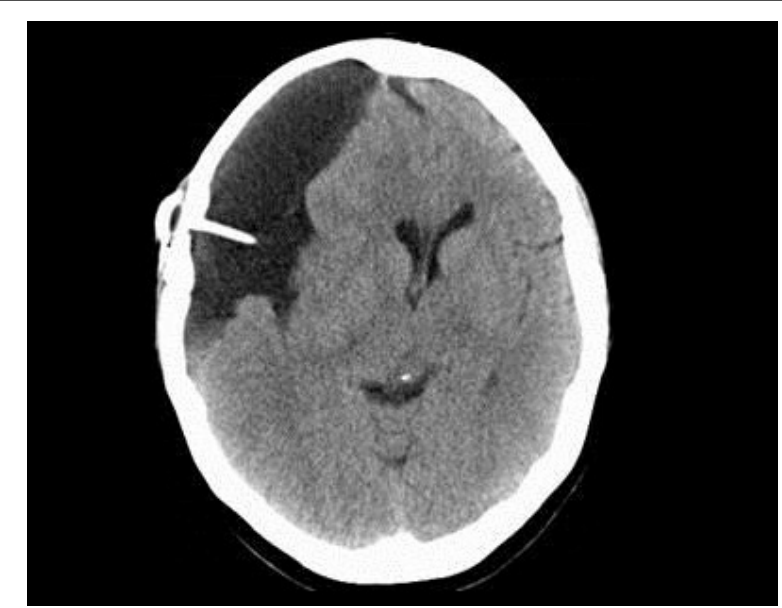

Figure 8: Axial non-contrast CT brain showing arachnoid cyst causing mass effect. Shunt blocked and shunt revision required

Surgical management of arachnoid cysts will depend on the location, the operative risk profile, the willingness of the patient to avoid a shunt and the chance of recurrence. Fenestration, which is the creation of a communication between the cyst and the subarachnoid space or ventricle may be suitable for cyst management. This technique has been shown to have good results for arachnoid cysts in most locations [8, 31]. Ventriculocystostomy or ventriculo-cystocysternostomy are also successful long-term treatments for arachnoid cysts in the suprasellar region [32]. Fenestration, at least initially, avoids placement of a shunt and can nowadays be carried out by minimally invasive endoscopic or microsurgical techniques [22]. However, recurrence of symptoms may occur, requiring shunt placement later [31]. Shunting may be required if addressing the cyst first fails to alleviate the hydrocephalus.

In spinal arachnoid cysts, either simple fenestration or a limited laminectomy with resection of the dural defect can be performed, with neither technique having significant differences in clinical outcomes. However, more invasive open or repeated laminectomies are associated with complications such as kyphoscoliosis [28].

In the setting of hydrocephalus, shunting is usually warranted by either cysto-peritoneal or cysto-subdural techniques (Figure 8) [31]. Shunt placement is associated with good results in terms of cyst treatment, but has a relatively high rate of further procedures due to shunt blockages and revisions [31]. Complete resection of intracranial arachnoid cysts requires craniotomy, and temporal cysts are more often treated in this way as an endoscopic approach in this area may be challenging [8].

There is ongoing debate about the optimal management of arachnoid cysts as the majority of arachnoid cysts are asymptomatic and harmless. In cysts proven to be symptomatic, however, the above procedures appear to have satisfactory results.

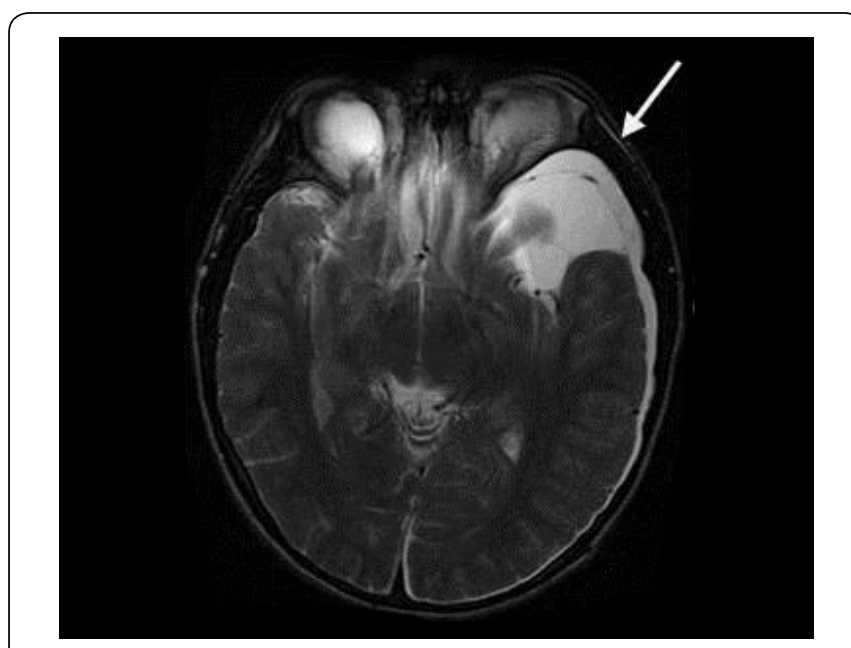

Figure 9: Axial T2 MR Images showing left temporal arachnoid cyst with chronic left sided subdural haematoma (arrow).

\section{Conclusion}

Arachnoid cysts are most commonly an incidental discovery on neuroimaging and have for the most part, a benign natural history. They comprise $1 \%$ of intracranial masses and are more common in males. Increasingly, arachnoid cysts are being discovered at earlier ages due to more widespread use of antenatal and cross-sectional imaging.

For the few that cause symptoms, their clinical presentation will depend on their location and the adjacent structures onto which they cause mass effect on. They also may present with hemorrhage or rupture. Treatment is generally reserved for symptomatic cysts with a range of neurosurgical techniques available.

\section{References}

1. Gosalakkal JA. 2002. Intracranial arachnoid cysts in children: a review of pathogenesis, clinical features, and management. Pediatr Neurol 


\section{6(2): 93-98. doi: 10.1016/S0887-8994(01)00329-0}

2. Al-Holou WN, Terman S, Kilburg C, Garton HJ, Muraszko KM, et al. 2013. Prevalence and natural history of arachnoid cysts in adults. $J$ Neurosurg 118(2): 222-231. doi: 10.3171/2012.10.JNS12548

3. Katzman GL, Dagher AP, Patronas NJ. 1999. Incidental findings on brain magnetic resonance imaging from 1000 asymptomatic volunteers. JAMA 282(1): 36-39. doi: 10.1001/jama.282.1.36

4. Pierre-Kahn A, Hanlo P, Sonigo P, Parisot D, McConnell RS. 2000. The contribution of prenatal diagnosis to the understanding of malformative intracranial cysts: state of the art. Childs Nerv Syst 16(10-11): 618-626. doi: $10.1007 / \mathrm{s} 003810000316$

5. Wang HS, Kuo MF, Huang SC, Chou ML, Hung PC, et al. 2002. Transcranial ultrasound diagnosis of intracranial lesions in children with headaches. Pediatr Neurol 26(1): 43-46. doi: 10.1016/S08878994(01)00372-1

6. Bretelle F, Senat MV, Bernard JP, Hillion Y,Ville Y.2002. First-trimester diagnosis of fetal arachnoid cyst: prenatal implication. Ultrasound Obstet Gynecol 20(4): 400-402. doi: 10.1046/j.1469-0705.2002.00813.x

7. Al-Holou WN, Yew AY, Boomsaad ZE, Garton HJ, Muraszko KM, et al. 2010. Prevalence and natural history of arachnoid cysts in children. J Neurosurg Pediatr 5(6): 578-585. doi: 10.3171/2010.2.PEDS09464

8. Westermaier T, Schweitzer T, Ernestus RI. 2012. Arachnoid cysts. Adv Exp Med Biol 724: 37-50. doi: 10.1007/978-1-4614-0653-2_3

9. Weber F, Knopf H. 2004. Cranial MRI as a screening tool: findings in 1,772 military pilot applicants. Aviat Space Environ Med 75(2): 158161.

10. Yousem DM, Grossman RI. 2010. Neuroradiology: The Requisites, 3rd edition, Mosby/Elsevier, Philadelphia, PA, USA

11. Campistol Plana J, Costa Clara JM, Fernandez-Alvarez E. 1983. Intracranial arachnoid cysts in children. Review of 34 cases. An Esp Pediatr 19(6): 459-470.

12. Rengachary SS, Watanabe I. 1981. Ultrastructure and pathogenesis of intracranial arachnoid cysts. J Neuropathol Exp Neurol 40(1): 61-83. doi: 10.1097/00005072-198140010-00007

13. Santamarta D, Aguas J, Ferrer E. 1995. The natural history of arachnoid cysts: endoscopic and cine-mode MRI evidence of a slit-valve mechanism. Minim Invasive Neurosurg 38(4): 133-137. doi: 10.1055/s2008-1053473

14. Cagnoni G, Fonda C, Pancani S, Pampaloni A, Mugnaini L. 1996. Intracranial arachnoid cyst in pediatric age. Pediatr Med Chir 18(1) $85-90$.

15. Go KG, Houthoff HJ, Blaauw EH, Havinga P, Hartsuiker J. 1984 Arachnoid cysts of the sylvian fissure. Evidence of fluid secretion. $J$ Neurosurg 60(4): 803-813. doi: 10.3171/jns.1984.60.4.0803

16. Becker T, Wagner M, Hofmann E, Warmuth-Metz M, Nadjmi M. 1991. Do arachnoid cysts grow? A retrospective CT volumetric study. Neuroradiology 33(4): 341-345. doi: 10.1007/BF00587820

17. Dutt SN, Mirza S, Chavda SV, Irving RM. 2002. Radiologic differentiation of intracranial epidermoids from arachnoid cysts. Otol Neurotol 23(1): 84-92.
18. Silbergleit R, Brunberg JA, Patel SC, Mehta BA, Aravapalli SR. 1998. Imaging of spinal intradural arachnoid cysts: MRI, myelography and CT. Neuroradiology 40(10): 664-668. doi: 10.1007/s002340050661

19. Chen CY, Wong JS, Hsieh SC, Chu JS, Chan WP. 2006. Intracranial epidermoid cyst with hemorrhage: MR imaging findings. AJNR Am J Neuroradiol 27(2): 427-429.

20. Gedikbasi A, Palabiyik F, Oztarhan A, Yildirim G, Eren C, et al. 2010. Prenatal diagnosis of a suprasellar arachnoid cyst with 2- and 3-dimensional sonography and fetal magnetic resonance imaging: difficulties in management and review of the literature. $J$ Ultrasound Med 29(10): 1487-1493.

21. Galassi E, Tognetti F, Gaist G, Fagioli L, Frank F, et al. 1982. CT scan and metrizamide CT cisternography in arachnoid cysts of the middle cranial fossa: classification and pathophysiological aspects. Surg Neurol 17(5): 363-369. doi: 10.1016/0090-3019(82)90315-9

22. Pradilla G, Jallo G. 2007. Arachnoid cysts: case series and review of the literature. Neurosurg Focus 22(2): E7.

23. Helland CA, Wester K. 2007. A population based study of intracranial arachnoid cysts: clinical and neuroimaging outcomes following surgical cyst decompression in adults. J Neurol Neurosurg Psychiatry 78(10): 1129-1135. doi: 10.1136/jnnp.2006.107995

24. Lütcherath V, Waaler PE, Jellum E, Wester K. 2000. Children with bilateral temporal arachnoid cysts may have glutaric aciduria type 1 (GAT1); operation without knowing that may be harmful. Acta Neurochir (Wien) 142(9): 1025-1030. doi: 10.1007/s007010070058

25. Erdincler P, Kaynar MY, Bozkus H, Ciplak N. 1999. Posterior fossa arachnoid cysts. $\mathrm{Br} J$ Neurosurg 13(1): 10-17. doi: $10.1080 / 02688699944122$

26. Adan L, Bussieres L, Dinand V, Zerah M, Pierre-Kahn A, et al. 2000. Growth, puberty and hypothalamic-pituitary function in children with suprasellar arachnoid cyst. Eur J Pediatr 159(5): 348-355. doi: 10.1007/ s004310051285

27. Wiese JA, Gentry LR, Menezes AH. 1985. Bobble-head doll syndrome: review of the pathophysiology and CSF dynamics. Pediatr Neurol 1(6): 361-366. doi: 10.1016/0887-8994(85)90073-6

28. Lee CH, Hyun SJ, Kim KJ, Jahng TA, Kim HJ. 2012. What is a reasonable surgical procedure for spinal extradural arachnoid cysts: is cyst removal mandatory? Eight consecutive cases and a review of the literature. Acta Neurochir (Wien) 154(7): 1219-1227. doi: 10.1007/ s00701-012-1356-7

29. National Guideline Clearing House. ACR Appropriateness Criteria ${ }^{\circledR}$ myelopathy.

30. Kwak YS, Hwang SK, Park SH, Park JY. 2013. Chronic subdural hematoma associated with the middle fossa arachnoid cyst: pathogenesis and review of its management. Childs Nerv Syst 29(1): 77-82. doi: 10.1007/s00381-012-1896-4

31. Raffel C, McComb JG. 1988. To shunt or to fenestrate: which is the best surgical treatment for arachnoid cysts in pediatric patients? Neurosurgery 23(3): 338-342.

32. Greenberg MS. 2010. Handbook of Neurosurgery. Thieme, New York, USA 